\title{
Probing the Analogy Between Living Crystallization-Driven Self- Assembly and Living Covalent Polymerizations: Length- Independent Growth Behavior for 1D Block Copolymer Nanofibers
}

Shixing Lei ${ }^{1}$, Jia Tian ${ }^{1, \hbar}$, Tomoya Fukui ${ }^{1, \dagger}$, Mitchell A. Winnik ${ }^{2, *}$, and Ian Manners ${ }^{1, *}$

${ }^{1}$ Department of Chemistry, University of Victoria, Victoria, British Columbia, V8W 3V6, Canada ${ }^{2}$ Chemistry Department, University of Toronto, 80 St. George Street, Toronto, M5S 3H6, Canada Present address: Key Laboratory of Synthetic and Self-Assembly Chemistry for Organic Functional Molecules, Shanghai Institute of Organic Chemistry, Chinese Academy of Sciences, Shanghai 200032, China

†Present address: Tokyo Institute of Technology, R1-1, 4259 Nagatsuta, Midori-ku, Yokohama, Kanagawa, 226-8503, Japan

*Correspondence to: $\underline{\text { imanners@uvic.ca or } \text { m.winnik@utoronto.ca }}$

\section{Table of Contents}

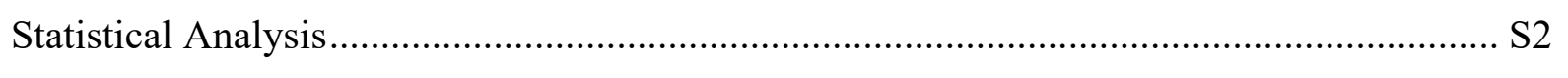

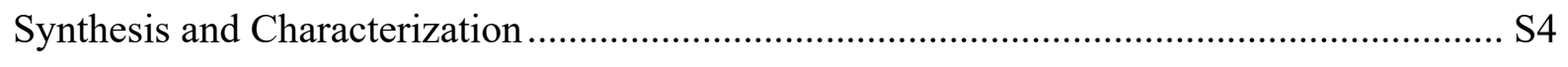

Experimental Procedures for Living CDSA Experiments .................................................. S7

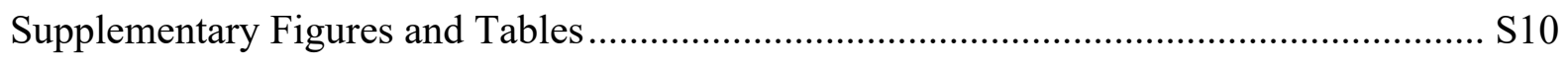




\section{Statistical Analysis}

The number-average length $\left(L_{n}\right)$, weight-average length $\left(L_{w}\right)$, and polydispersity index (PDI) of micelles length were calculated by using supplementary equations S1-S3 from the measurements of the contour length $\left(L_{i}\right)$ of individual micelles, where $N_{\mathrm{i}}$ is the number of the fibers of length $L_{\mathrm{i}}$, and $n$ is the number of micelles examined in each sample.

$$
\begin{gathered}
L_{n}=\frac{\sum_{i=1}^{n} N_{i} L_{i}}{\sum_{i=1}^{n} N_{i}} \\
L_{w}=\frac{\sum_{i=1}^{n} N_{i} L_{i}^{2}}{\sum_{i=1}^{n} N_{i} L_{i}} \\
\text { PDI }=\frac{L_{w}}{L_{n}}
\end{gathered}
$$

Nonlinear regressions of length distributions for low dispersity 1D micelles and micelles after living CDSA experiments with 1D micelles of different lengths were based on a Gaussian function (Eq. S4) and a bivariate Gaussian function (Eq. S5) respectively.

$$
\begin{gathered}
f(x)=a \cdot \exp \left\{-\frac{\left(x-L_{M E A N}\right)^{2}}{2 \sigma^{2}}\right\} \\
f(x)=\alpha \cdot \exp \left\{-\frac{\left(x-L_{\alpha M E A N}\right)^{2}}{2 \sigma_{\alpha}{ }^{2}}\right\}+\beta \cdot \exp \left\{-\frac{\left(x-L_{\beta M E A N}\right)^{2}}{2 \sigma_{\beta}{ }^{2}}\right\}
\end{gathered}
$$

The standard deviations $(\sigma)$ of the measured lengths are related to length dispersity $\left(L_{w} / L_{n}\right)$ through the following expression (Eq. S6).

$$
\frac{L_{w}}{L_{n}}-1=\left(\frac{\sigma}{L_{n}}\right)^{2}
$$

The standard deviations $(\sigma)$ of the newly grown lengths are calculated based on the following equation (Eq. S7), where $\mathrm{X}$ and $\mathrm{Y}$ represent two random variables, while $\sigma(\mathrm{X})$ and $\sigma(\mathrm{Y})$ represent their individual standard deviations. 


$$
\sigma(X+Y)=\sqrt{\sigma(X)^{2}+\sigma(Y)^{2}}
$$

The uncertainty of the mean of a micelle length population is described as standard deviation of the population mean $\left(S D_{\bar{x}}\right)$, which is calculated based on the following equation (Eq. S8), where $\sigma$ represents the standard deviation $(\sigma)$ of the measured lengths and $n$ is the number of micelles examined in each sample.

$$
S D_{\bar{x}}=\frac{\sigma}{\sqrt{n}}
$$

Eq. S8

The uncertainty of the regression in a simple linear regression is quantified by the standard deviation of the residuals $\left(S_{y \cdot x}\right)$, where the residual is the vertical distance (in y units) of the point from the fit line. $S_{y . x}$ is calculated based on the following equation (Eq. S9), where $\mathrm{n}$ is the number of points and $\mathrm{K}$ is the number of parameters fit by regression. The value $n-K$ is the number of degrees of freedom of the regression.

The uncertainty of the slope in a simple linear regression is expressed as the standard error (or deviation) of the slope $\left(S_{b}\right)$ and is calculated based on uncertainty of regression (standard deviation of the residuals, $S_{y \cdot x}$ ) as shown in the following equation (Eq. S10).

$$
\begin{gathered}
S_{y \cdot x}=\sqrt{\frac{\sum\left(\text { residual }^{2}\right)}{n-K}} \\
S_{b}=\frac{S_{y \cdot x}}{\sqrt{\sum\left(x_{i}-\bar{x}\right)^{2}}}
\end{gathered}
$$




\section{Synthesis and Characterization}

a
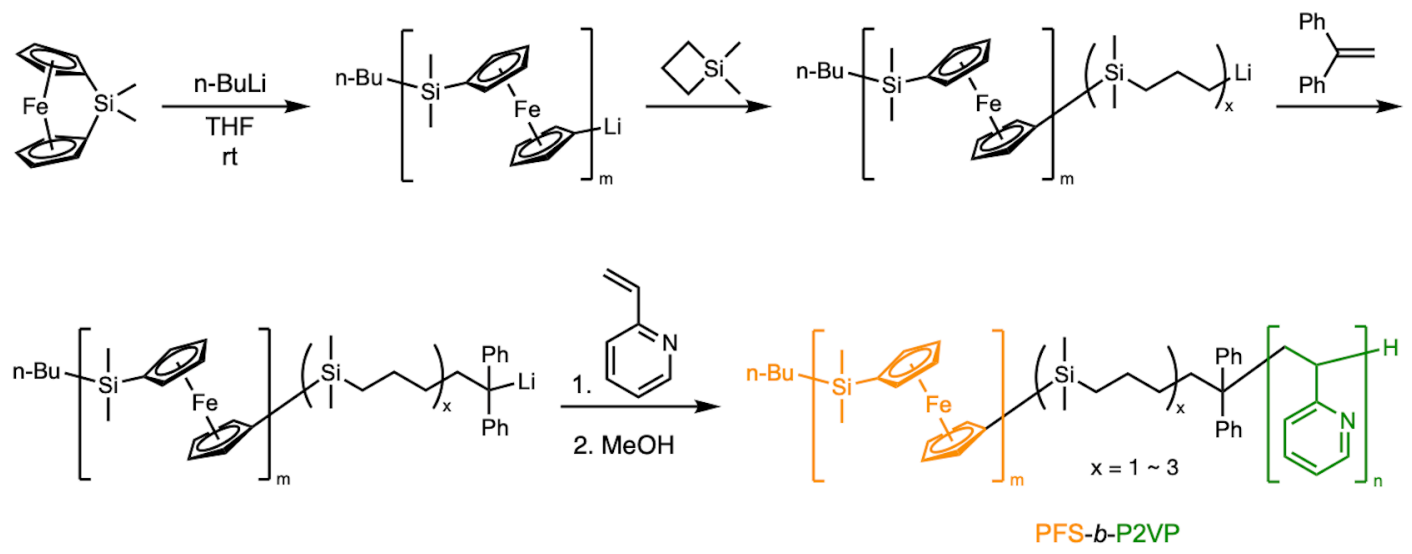

b

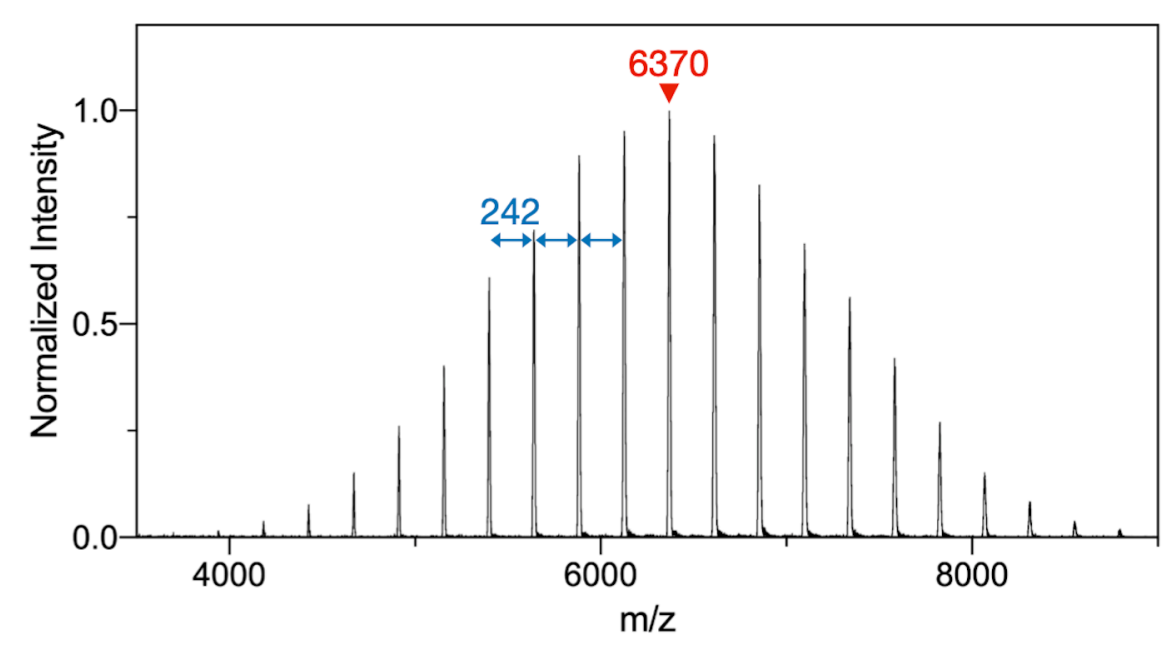

c
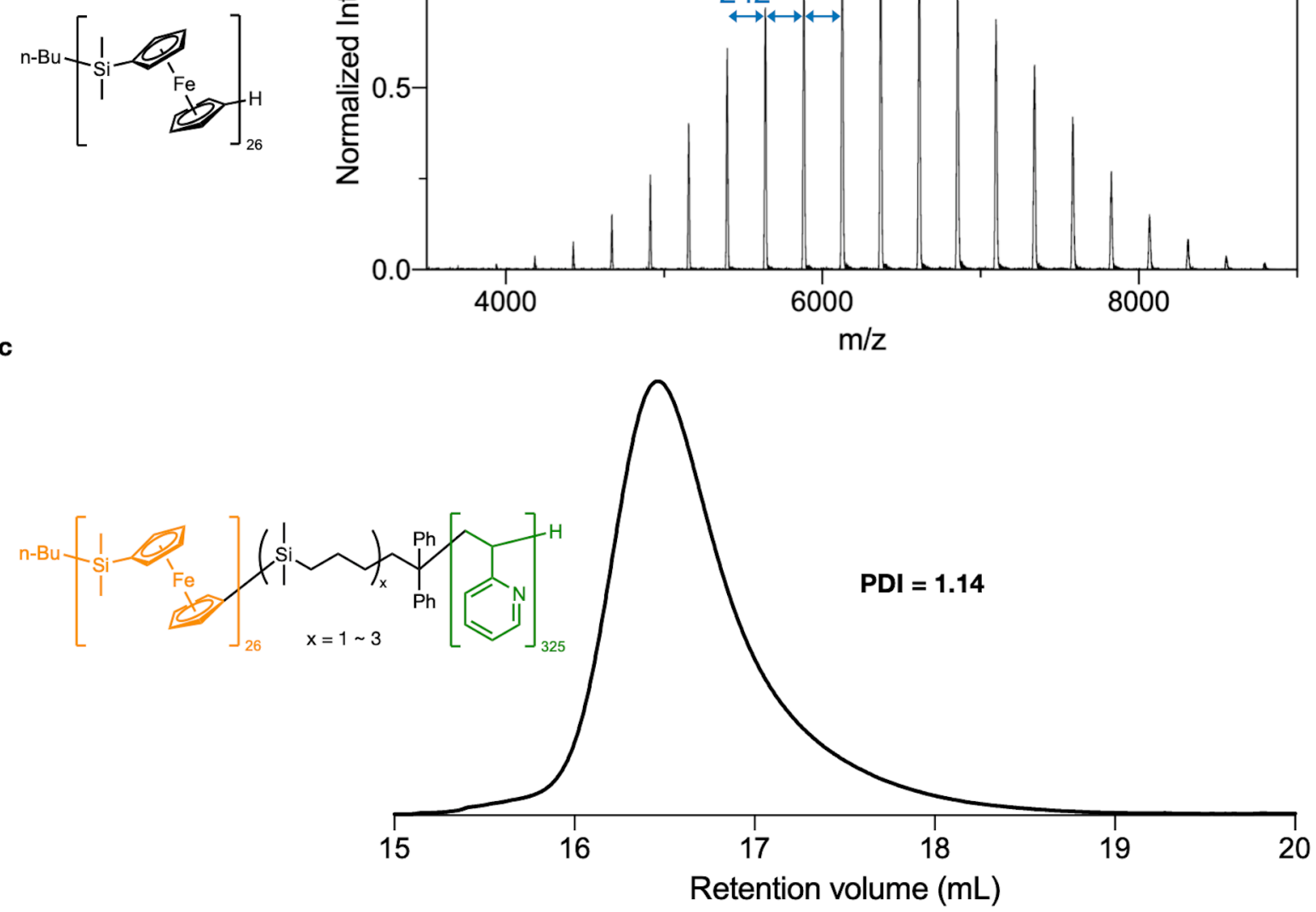

Figure S1. (a) Synthetic route to $\mathrm{PFS}_{26}-b$-P2VP 325 . (b) MALDI-TOF mass spectrum of $\mathrm{PFS}_{26}$ homopolymer from the aliquot quenched before the second step of the polymerization for $\mathrm{PFS}_{26}-b-\mathrm{P} 2 \mathrm{VP}_{325}$. The repeat unit for PFS was $242 \mathrm{~m} / z$. (c) GPC chromatograms of $\mathrm{PFS}_{26}-b$-P2 $\mathrm{VP}_{325}$ using a refractive index detector. THF containing triethylamine $(1 \% \mathrm{w} / \mathrm{w})$ was used as the eluent. 
a
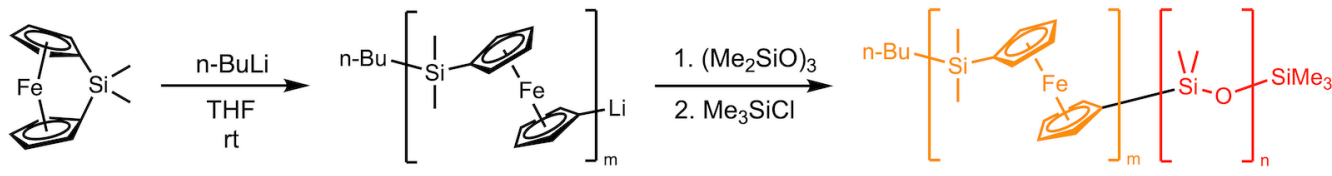

PFS-b-PDMS

b
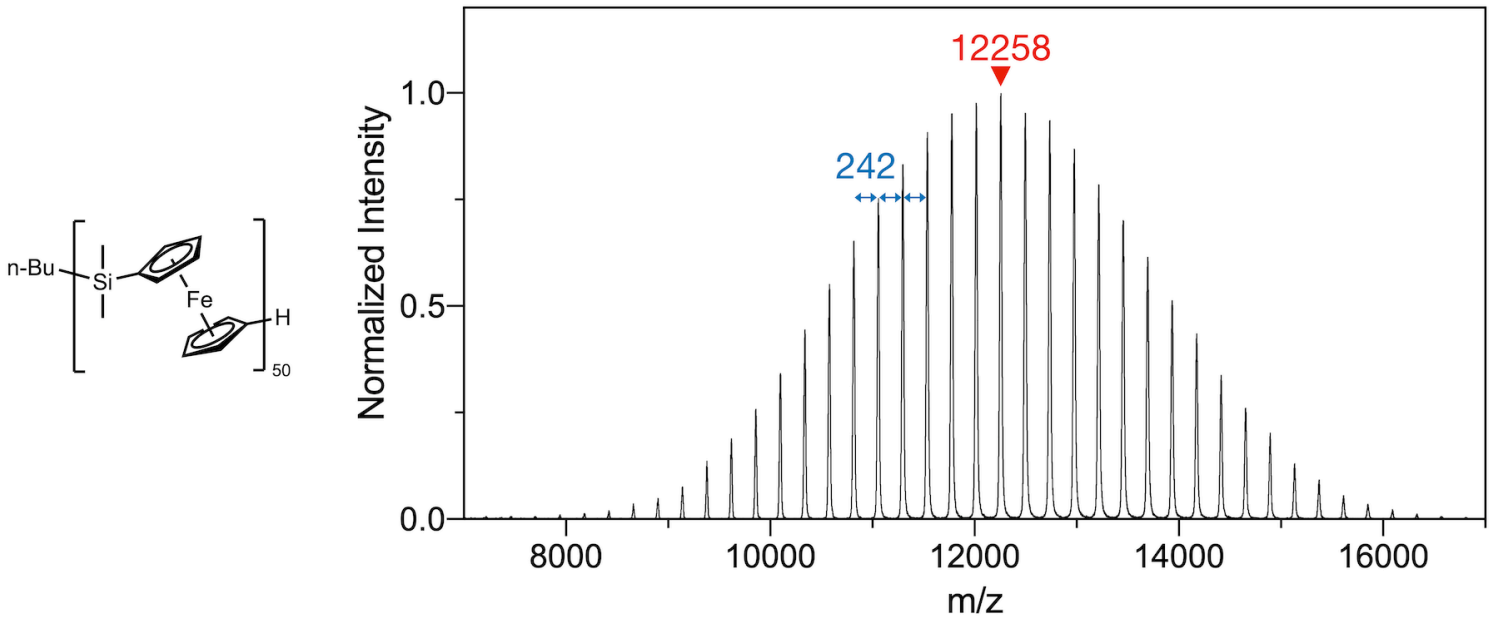

c
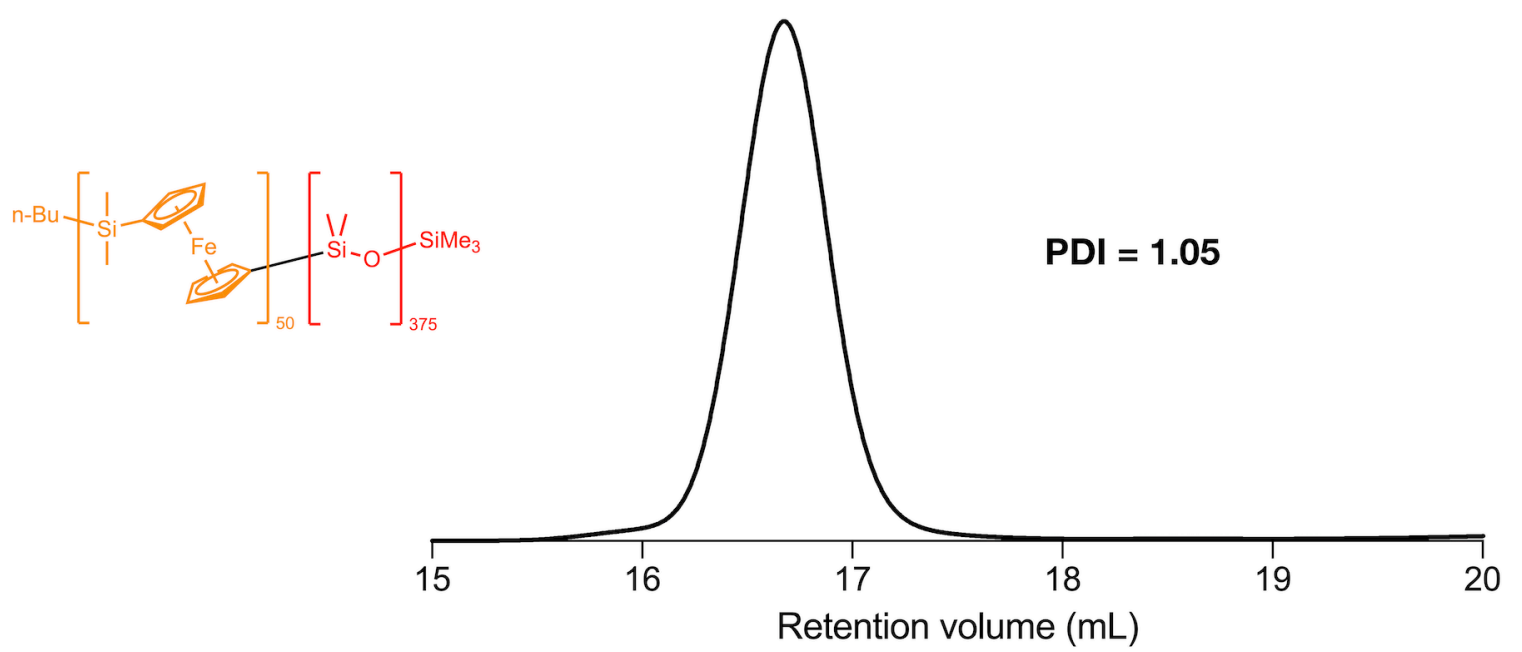

Figure S2. (a) Synthetic route to $\mathrm{PFS}_{50}-b-\mathrm{PDMS}_{375}$. (b) MALDI-TOF MS spectrum of $\mathrm{PFS}_{50}$ homopolymer from the aliquot quenched before the second step of the polymerization for $\mathrm{PFS}_{50}-b$-PDMS 375 . The repeat unit for PFS was $242 \mathrm{~m} / z$. (c) GPC chromatograms of $\mathrm{PFS}_{50}-b$-PDMS 375 using a refractive index detector. THF containing triethylamine $(1 \% \mathrm{w} / \mathrm{w})$ was used as the eluent. 
a

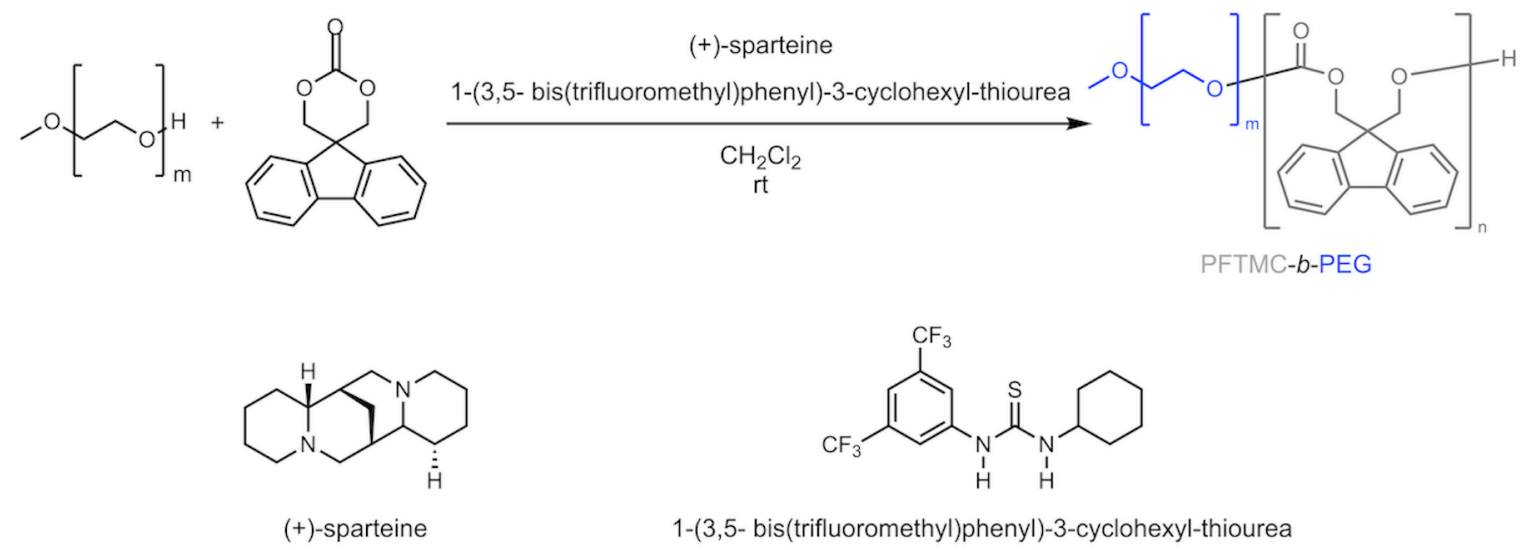

b

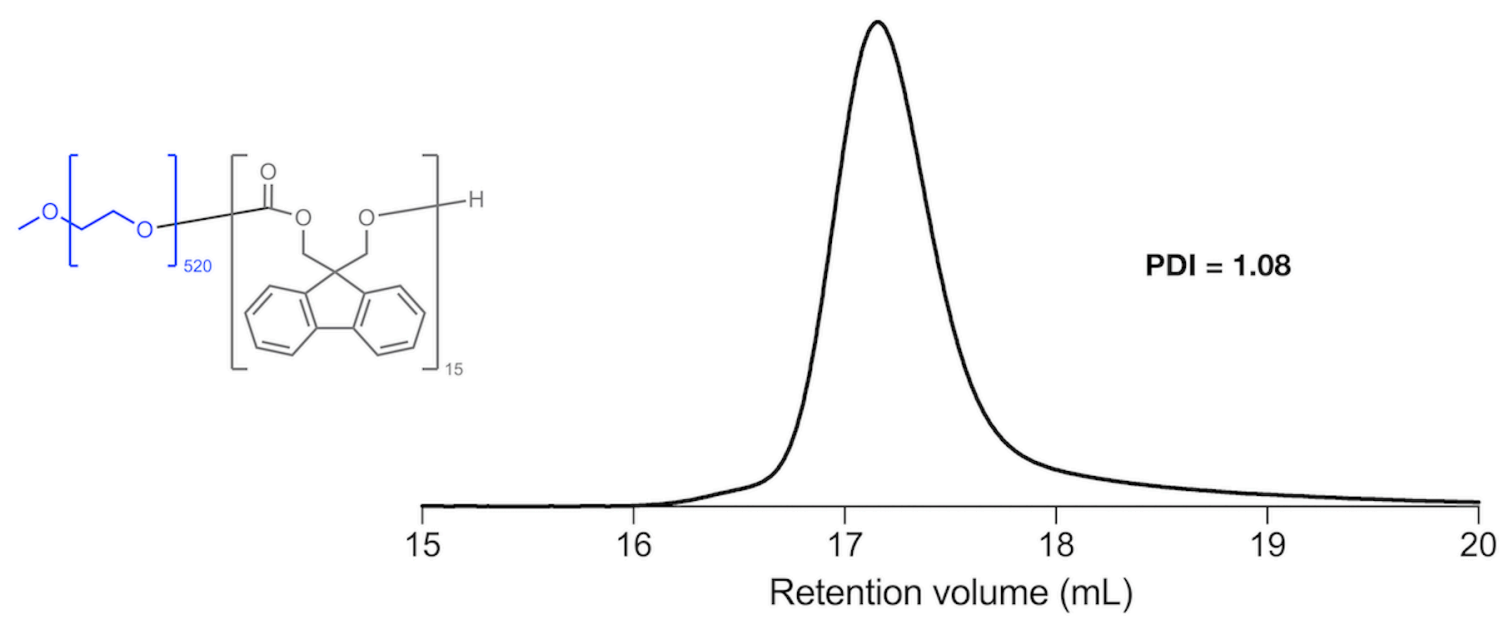

Figure S3. (a) Synthetic route to PFTMC $15-b-\mathrm{PEG}_{520}$. (b) GPC chromatograms of PFTMC $15-b-\mathrm{PEG}_{520} \mathrm{using}_{5}$ a refractive index detector. THF containing triethylamine $(1 \% \mathrm{w} / \mathrm{w})$ was used as the eluent.

\section{BCP molar mass characterization}

$\mathrm{PFS}_{26}-b-\mathrm{P}_{2} \mathrm{VP}_{325}$ and $\mathrm{PFS}_{50}-b-\mathrm{PDMS}_{375}$ : The number-average molar mass $\left(M_{\mathrm{n}}\right)$ and numberaverage degree of polymerization $\left(\mathrm{DP}_{\mathrm{n}}\right)$ of the BCPs were determined by using both ${ }^{1} \mathrm{H}$ NMR and MALDI-TOF-MS. Aliquots of the first block were taken and the $M_{\mathrm{n}}$ of the first block was determined by MALDI-TOF-MS. The polymerization degrees of the second blocks were then determined by combining the $M_{\mathrm{n}}$ of the first block with the block ratio of the diblock copolymer which was obtained by integration of the ${ }^{1} \mathrm{H}$ NMR spectrum. The polydispersity indices (PDIs) of the synthesized BCPs were determined by GPC measurements.

$\mathrm{PFTMC}_{15}-b-\mathrm{PEG}_{520}$ : The values of $M_{\mathrm{n}}$ and $\mathrm{DP}_{\mathrm{n}}$ for each block and the block ratio of the BCP were determined by end-group analysis using ${ }^{1} \mathrm{H}$ NMR. The methyl end-group protons were used for this purpose. The polydispersity index (PDI) of the synthesized BCP was determined by GPC. 


\section{Experimental Procedures for Living CDSA Experiments}

\section{Preparation of polydisperse $1 D$ fiber-like micelles $\left(\mathrm{PFS}_{26}-b-\mathrm{P} 2 \mathrm{VP}_{325}\right)$}

Isopropanol solution of $\mathrm{PFS}_{26}-b-\mathrm{P}_{2} \mathrm{VP}_{325}$ (conc. $=0.2 \mathrm{mg} / \mathrm{mL}$ ) was heated at $80{ }^{\circ} \mathrm{C}$ for $3 \mathrm{~h}$. The clear yellow solution was cooled to ambient temperature $\left(22^{\circ} \mathrm{C}\right)$ slowly and aged for $48 \mathrm{~h}$.

\section{Preparation of seed micelles $\left(\mathrm{PFS}_{26}-b-\mathrm{P}_{2} \mathrm{VP}_{325}\right)$}

The polydisperse 1D fiber-like micelles were fragmented by sonication at $0{ }^{\circ} \mathrm{C}$ for $3 \mathrm{~h}$ to yield short micelles. The lengths of resulting seeds were evaluated by TEM analysis.

\section{Living CDSA for preparing low dispersity micelles of different length (using PFS $_{26}-b$ - P2VP 325$)$}

The solution of the seeds (conc. $=0.2 \mathrm{mg} / \mathrm{mL}$ ) was diluted by $90 \% \mathrm{v} / \mathrm{v}$ isopropanol/THF to $0.025 \mathrm{mg} / \mathrm{mL}$. To the seed micelles, appropriate amounts of unimers in THF were added respectively $\left(m_{\text {unimer }} / m_{\text {seed }}=0,5,10,20\right.$, and 60). After mechanical shaking for $10 \mathrm{~s}$, the solutions were aged for $48 \mathrm{~h}$ at $22^{\circ} \mathrm{C}$. TEM analyses evaluated the contour length of the resulting micelles. (Note that in cases where the concentration of the resulting micelles was too high for effective TEM analysis the sample solutions were diluted appropriately beforehand).

\section{Living CDSA experiments using 1D fiber-like micelles of different lengths in a polar solvent medium (using PFS $_{26}-b-P 2 V P_{325}$ )}

Solutions of mixed seeds were prepared by combining the same volume of low dispersity micelle samples of different lengths (conc. of original seeds $=0.025 \mathrm{mg} / \mathrm{mL}$ ). After thoroughly mixing, appropriate amounts of unimers in THF were added respectively $\left[m_{\text {unimer }} / m_{\text {seed }}=10,20\right.$, and 30 , where $m_{\text {seed }}$ represents the mass of original (ca. $17.1 \mathrm{~nm}$ ) seeds used for preparing the low dispersity ca. $100 \mathrm{~nm}$ and ca. $1000 \mathrm{~nm}$ micelle samples]. After mechanical shaking for $10 \mathrm{~s}$, the solutions were aged for $24 \mathrm{~h}$ at $22^{\circ} \mathrm{C}$. TEM analyses evaluated the contour length of the resulting micelles. [Temperature-dependent experiments were performed at elevated temperature $\left(35^{\circ} \mathrm{C}\right)$ following the same protocol]

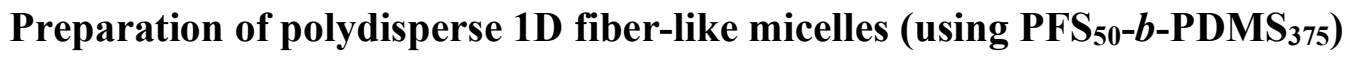

Hexane solution of $\mathrm{PFS}_{50}-b-\mathrm{PDMS}_{375}$ (conc. $=0.5 \mathrm{mg} / \mathrm{mL}$ ) was heated at $66^{\circ} \mathrm{C}$ for $1.5 \mathrm{~h}$. The clear yellow solution was cooled to ambient temperature $\left(22^{\circ} \mathrm{C}\right)$ slowly and aged for $48 \mathrm{~h}$. 


\section{Preparation of seed micelles (using PFS $_{50}-b$-PDMS 375 )}

The polydisperse 1D fiber-like micelles were fragmented by sonication at $-78^{\circ} \mathrm{C}$ for $1.5 \mathrm{~h}$ to yield short micelles. The lengths of resulting seeds were evaluated by TEM analysis.

\section{Living CDSA for preparing low dispersity micelles of different lengths (using PFS50- $b$ - PDMS $_{375)}$}

The solution of the seeds (conc. $=0.5 \mathrm{mg} / \mathrm{mL}$ ) was diluted by $\mathrm{n}$-hexane to $0.025 \mathrm{mg} / \mathrm{mL}$. To the seed micelles, appropriate amounts of unimers in THF were added respectively $\left(m_{\text {unimer }} / m_{\text {seed }}\right.$ $=0,2.5,5,10$, and 30). After the mechanical shaking for $10 \mathrm{~s}$, the solutions were aged for $48 \mathrm{~h}$ at $22{ }^{\circ} \mathrm{C}$. TEM analyses evaluated the contour length of the resulting micelles.

\section{Living CDSA experiments using 1D fiber-like micelles of different lengths in a non-polar solvent medium (using PFS $_{50}-b$-PDMS 375 )}

Solutions of mixed seeds were prepared by combining the same volume of low dispersity micelle samples of different lengths (conc. of original seeds $=0.025 \mathrm{mg} / \mathrm{mL}$ ). After thoroughly mixing, appropriate amounts of unimers in THF were added respectively $\left[m_{\text {unimer }} / m_{\text {seed }}=5,10\right.$, and 15 , where $m_{\text {seed }}$ represents the mass of the original (ca. $35.9 \mathrm{~nm}$ ) seeds used for preparing the low dispersity ca. $100 \mathrm{~nm}$ and ca. $1000 \mathrm{~nm}$ micelle samples]. After the mechanical shaking for $10 \mathrm{~s}$, the solutions were aged for $24 \mathrm{~h}$ at $22{ }^{\circ} \mathrm{C}$. TEM analyses evaluated the contour length of the resulting micelles.

\section{Living CDSA experiments using 1D fiber-like micelles of different lengths for preparing triblock co-micelles}

Solutions of mixed seeds were prepared by combining the same volume of low dispersity $\mathrm{PFS}_{50}-b$-PDMS 375 micelle samples of different lengths (in n-hexane) (conc. of original seeds $=$ $0.025 \mathrm{mg} / \mathrm{mL}$ ). Such mixed micelle samples were diluted to $0.01 \mathrm{mg} / \mathrm{mL}$ (conc. of original seeds) to a $75 \% \mathrm{v} / \mathrm{v}$ isopropanol $/ \mathrm{n}$-hexane solvent environment by slow addition of isopropanol and $\mathrm{n}$ hexane. After thoroughly mixing, appropriate amounts of $\mathrm{PFS}_{26}-b-\mathrm{P}_{2} \mathrm{VP}_{325}$ unimers in THF were added respectively $\left[m_{\text {unimer }} / m_{\text {seed }}=20,40\right.$, and 60 , where $m_{\text {seed }}$ represents the mass of original (ca. $35.9 \mathrm{~nm}$ ) seeds used for preparing the low dispersity ca. $100 \mathrm{~nm}$ and ca. $1000 \mathrm{~nm}$ micelle samples]. After the mechanical shaking for $10 \mathrm{~s}$, the solutions were aged for $24 \mathrm{~h}$ at $22^{\circ} \mathrm{C}$. TEM analyses evaluated the contour length of the resulting micelles. 


\section{Preparation of polydisperse 1D fiber-like micelles (using PFTMC 15-b-PEG520) $^{-}$}

$90 \% \mathrm{v} / \mathrm{v}$ Methanol/DMSO solution of $\mathrm{PFTMC}_{15}-b-\mathrm{PEG}_{520}($ conc. $=0.5 \mathrm{mg} / \mathrm{mL}$ ) was heated at $65^{\circ} \mathrm{C}$ for $3 \mathrm{~h}$. The clear solution was cooled to ambient temperature $\left(22^{\circ} \mathrm{C}\right)$ slowly and aged for $48 \mathrm{~h}$.

\section{Preparation of seed micelles (using PFTMC P $_{15} b-$ PEG $_{520}$ )}

The polydisperse 1D fiber-like micelles were fragmented by sonication at $15^{\circ} \mathrm{C}$ for $1.5 \mathrm{~h}$ to yield short micelles. The lengths of resulting seeds were evaluated by TEM analysis.

\section{Living CDSA for preparing low dispersity micelles of different lengths (PFTMC $15-b$-PEG 52 )}

The solution of the seeds (conc. $=0.5 \mathrm{mg} / \mathrm{mL}$ ) was diluted by Methanol to $0.025 \mathrm{mg} / \mathrm{mL}$. To the seed micelles, appropriate amounts of unimers in DMSO were added respectively $\left(m_{\text {unimer }} / m_{\text {seed }}\right.$ $=0,2.5,5,10$, and 25). After the mechanical shaking for $10 \mathrm{~s}$, the solutions were aged for $48 \mathrm{~h}$ at $22{ }^{\circ} \mathrm{C}$. TEM analyses evaluated the contour length of the resulting micelles.

\section{Living CDSA experiments using 1D fiber-like micelles of different lengths using crystallizable polycarbonate block copolymer (PFTMC $15-b$-PEG 520)}

Solutions of mixed seeds were prepared by combining the same volume of low dispersity micelle samples of different lengths (conc. of original seeds $=0.025 \mathrm{mg} / \mathrm{mL}$ ). After thoroughly mixing, appropriate amounts of unimers in DMSO were added respectively $\left[m_{\text {unimer }} / m_{\text {seed }}=5,10\right.$, and 15, where $m_{\text {seed }}$ represents the mass of the original (ca. $28.8 \mathrm{~nm}$ ) seeds used for preparing the low dispersity ca. $100 \mathrm{~nm}$ and ca. $1000 \mathrm{~nm}$ micelle samples]. After mechanical shaking for $10 \mathrm{~s}$, the solutions were aged for $24 \mathrm{~h}$ at $22{ }^{\circ} \mathrm{C}$. TEM analyses evaluated the contour length of the resulting micelles. 


\section{Supplementary Figures and Tables}

Use of Living CDSA for the preparation of low dispersity $\mathrm{PFS}_{26}-b-\mathrm{P}_{2} \mathrm{VP}_{325}$ 1D fiber-like micelles of different lengths

a

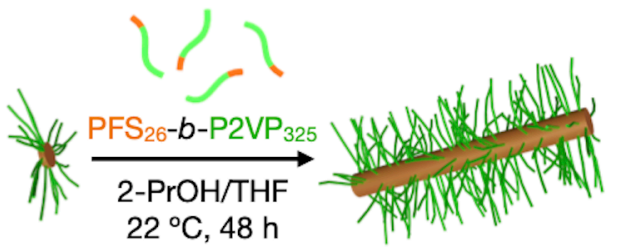

b

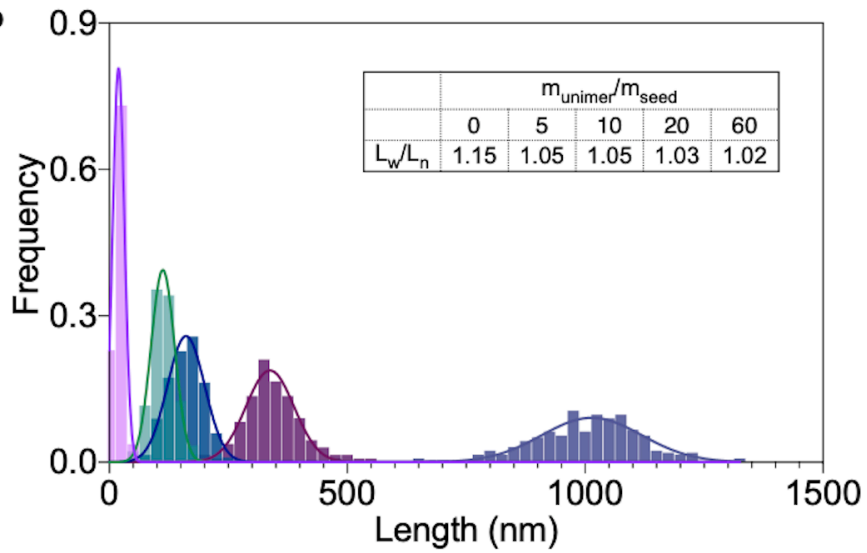

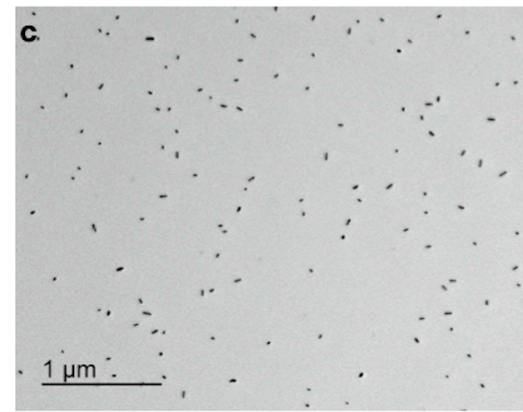

f

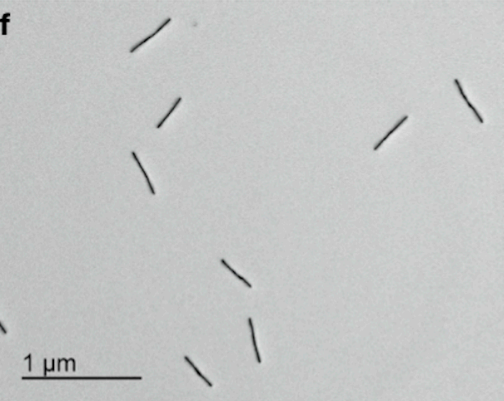

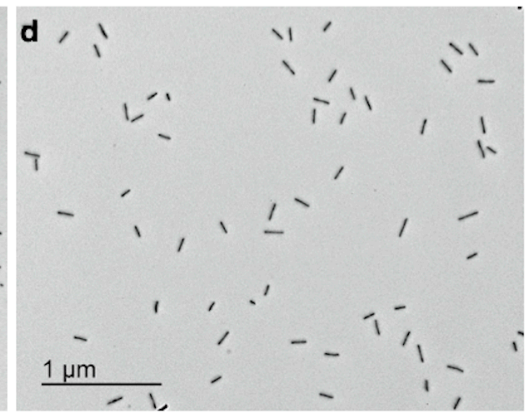

g

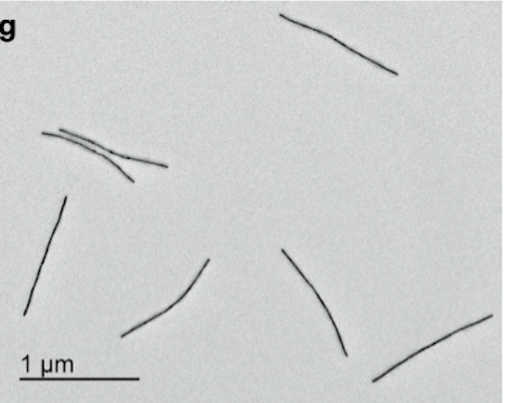

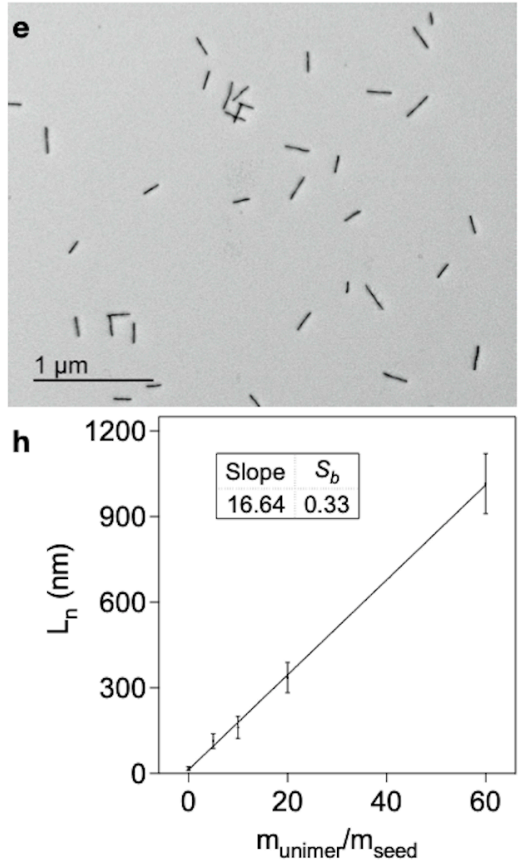

Figure S4. Living CDSA of $\mathrm{PFS}_{26}-b-\mathrm{P} 2 \mathrm{VP}_{325}$ in $90 \% \mathrm{v} / \mathrm{v}$ isopropanol/THF with varying $m_{\text {unimer }} / m_{\text {seed }}$ ratio for preparing low dispersity $1 \mathrm{D}$ fiber-like micelles. Experiments were performed with $0.025 \mathrm{mg} / \mathrm{mL}$ seeds micelles at ambient temperature $\left(22^{\circ} \mathrm{C}\right)$ for $48 \mathrm{~h}$. (a) Schematic representation of experiment design. (b) Statistical analysis (histograms and nonlinear regressions based on a Gaussian function) of micelle length distribution after living CDSA. The inset shows the polydispersity index (PDI $=L_{w} / L_{n}$ ) of each sample. (cg) Bright field TEM micrographs of dried 1D micelle mixture after living CDSA with $m_{\text {unimer }} / m_{\text {seed }}=0,5$, 10,20 , and 60 respectively. The seed $L_{n}=17.1 \mathrm{~nm}$ and corresponds to $m_{\text {unimer }} / m_{\text {seed }}=0$. (h) Linear regression of $L_{n}$ values upon different $m_{\text {unimer }} / m_{\text {seed }}$ ratio. Error bars represent standard deviation of the micelle length distribution. The inset shows the slope and $S_{b}$ (standard error) value for linear regression. 
Table S1. Statistical analysis of micelle length distribution after living CDSA of $\mathrm{PFS}_{26}-b-\mathrm{P} 2 \mathrm{VP}_{325}$ for preparing low dispersity $1 \mathrm{D}$ fiber-like micelles. $\sigma$ represents the standard deviation of the micelle length distribution.

\begin{tabular}{|c|c|c|c|c|c|}
\hline $\mathbf{m}_{\text {unimer }} / \mathbf{m}_{\text {seed }}$ & $\mathbf{0}(\mathbf{s e e d s})$ & $\mathbf{5}$ & $\mathbf{1 0}$ & $\mathbf{2 0}$ & $\mathbf{6 0}$ \\
\hline $\boldsymbol{L}_{\boldsymbol{n}}(\mathbf{n m})$ & 17.1 & 113.7 & 161.1 & 335.9 & 1015.6 \\
\hline $\boldsymbol{\sigma}(\mathbf{n m})$ & 6.7 & 25.7 & 38.5 & 52.9 & 105.5 \\
\hline Theoretical predicted $\boldsymbol{L}_{\boldsymbol{n}}(\mathbf{n m})$ & 17.1 & 102.6 & 188.1 & 342.2 & 1043.1 \\
\hline
\end{tabular}

Table S2. Linear regression results of $L_{n}$ values upon different $m_{\text {unimer }} / m_{\text {seed }}$ ratio after living CDSA of $\mathrm{PFS}_{26}-b-\mathrm{P} 2 \mathrm{VP}_{325}$ for preparing low dispersity $1 \mathrm{D}$ fiber-like micelles. $S_{b}$ represents the standard error of the slope.

\begin{tabular}{|l|c|c|c|}
\hline & Equation & $\mathbf{R}^{\mathbf{2}}$ & $\boldsymbol{S}_{\boldsymbol{b}}$ \\
\hline Low dispersity micelle & $\mathrm{y}=16.64 \mathrm{x}+12.49$ & 0.9988 & 0.33 \\
\hline
\end{tabular}




\section{Use of Living CDSA for the preparation of low dispersity PFS 50-b-PDMS $_{375}$ 1D fiber-like micelles of different lengths}

a

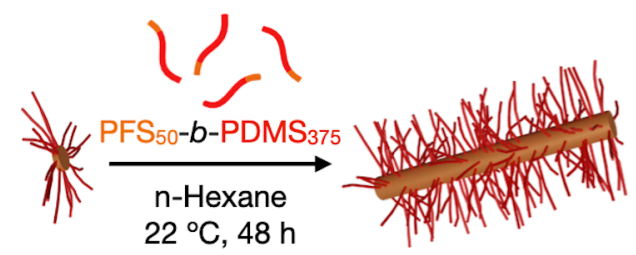

$22^{\circ} \mathrm{C}, 48 \mathrm{~h}$ b

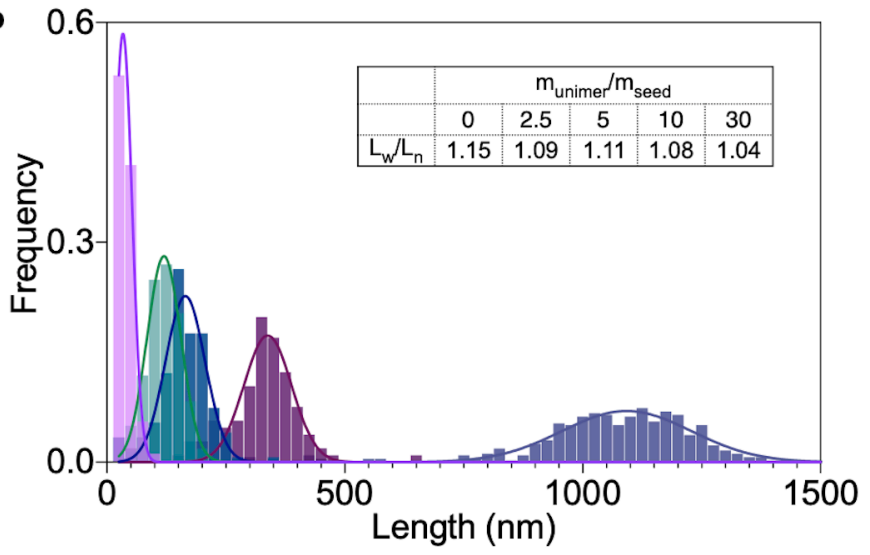

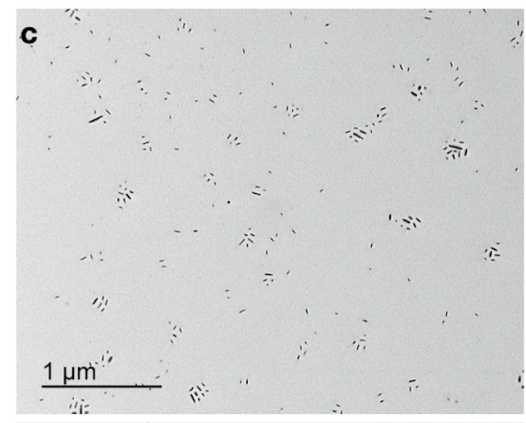
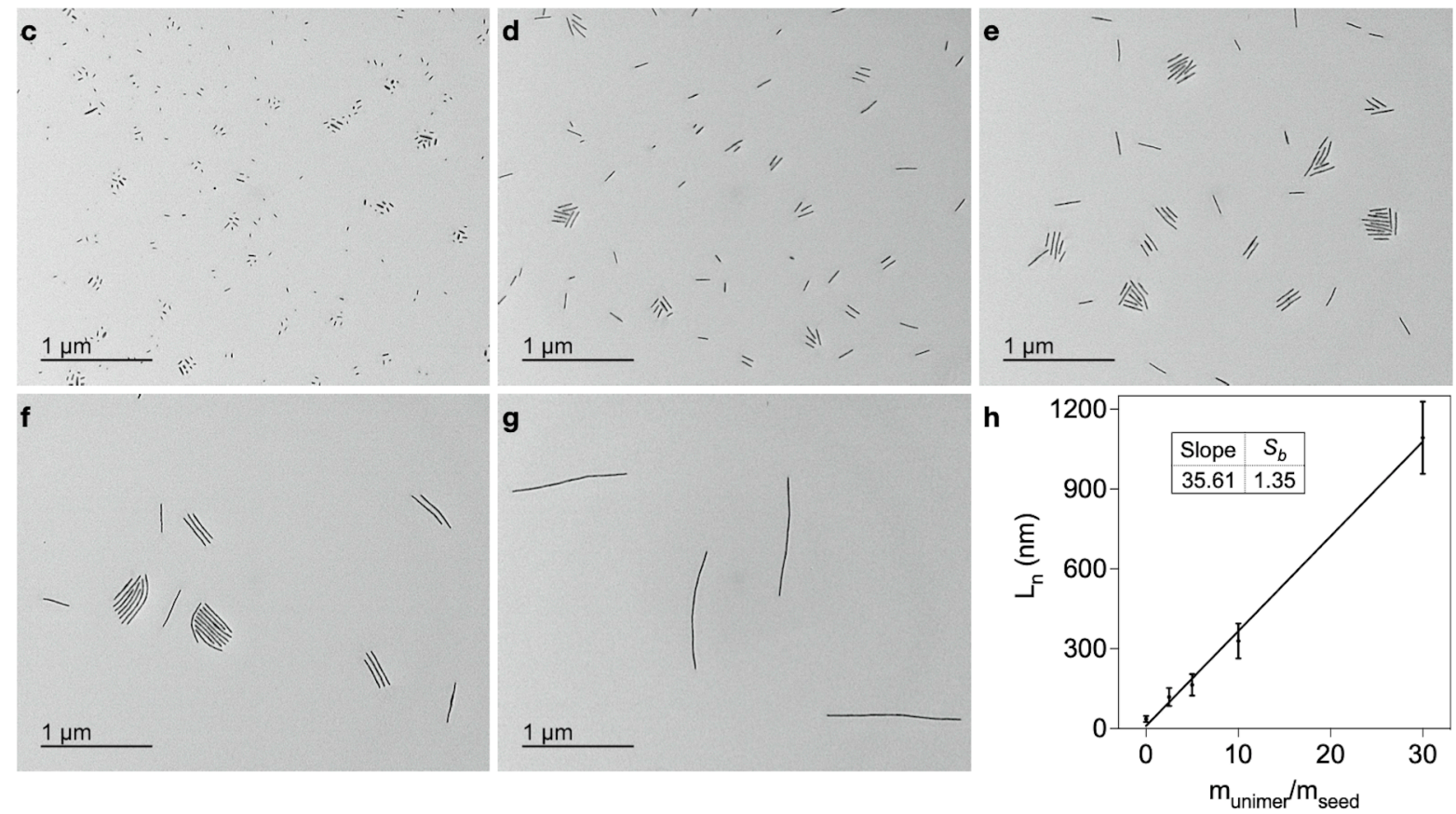

Figure S5. Living CDSA of $\mathrm{PFS}_{50}-b$-PDMS ${ }_{375}$ in n-hexane with varying $m_{\text {unimer }} / m_{\text {seed }}$ ratio for preparing low dispersity 1D fiber-like micelles. Experiments were performed with $0.025 \mathrm{mg} / \mathrm{mL}$ seeds micelles at ambient temperature $\left(22^{\circ} \mathrm{C}\right)$ for $48 \mathrm{~h}$. Unimer was added in THF (a) Schematic representation of experiment design. (b) Statistical analysis (histograms and nonlinear regressions based on a Gaussian function) of micelle length distribution after living CDSA. The inset shows the polydispersity index (PDI $\left.=L_{w} / L_{n}\right)$ of each sample. $(\mathrm{c}-\mathrm{g})$ Bright field TEM micrographs of dried 1D micelle mixture after living CDSA with $m_{\text {unimer }} / m_{\text {seed }}=0,2.5,5,10$, and 30 respectively. The seed $L_{n}=35.9 \mathrm{~nm}$ and corresponds to $m_{\text {unimer }} / m_{\text {seed }}=0$. (h) Linear regression of $L_{n}$ values upon different $m_{\text {unimer }} / m_{\text {seed }}$ ratio. Error bars represent standard deviation of the micelle length distribution. The inset shows the slope and $S_{b}$ (standard error) value for linear regression. 
Table S3. Statistical analysis of micelle length distribution after living CDSA of $\mathrm{PFS}_{50}-b$-PDMS 375 for preparing low dispersity $1 \mathrm{D}$ fiber-like micelles. $\sigma$ represents the standard deviation of the micelle length distribution.

\begin{tabular}{|c|c|c|c|c|c|}
\hline $\mathbf{m}_{\text {unimer }} / \mathbf{m}_{\text {seed }}$ & $\mathbf{0}(\mathbf{s e e d s})$ & $\mathbf{2 . 5}$ & $\mathbf{5}$ & $\mathbf{1 0}$ & $\mathbf{3 0}$ \\
\hline $\boldsymbol{L}_{\boldsymbol{n}}(\mathbf{n m})$ & 35.9 & 119.1 & 164.6 & 329.5 & 1092.8 \\
\hline $\boldsymbol{\sigma}(\mathbf{n m})$ & 11.6 & 33.8 & 40.2 & 65.8 & 135.9 \\
\hline Theoretical predicted $\boldsymbol{L}_{\boldsymbol{n}} \mathbf{( n m )}$ & 35.9 & 125.7 & 215.4 & 394.9 & 1112.9 \\
\hline
\end{tabular}

Table S4. Linear regression of $L_{n}$ values upon different $m_{\text {unimer }} / m_{\text {seed }}$ ratio after living CDSA of PFS ${ }_{50}-b$ PDMS $_{375}$ for preparing low dispersity $1 \mathrm{D}$ fiber-like micelles. $S_{b}$ represents the standard error of the slope.

\begin{tabular}{|l|c|c|c|}
\hline & Equation & $\mathbf{R}^{\mathbf{2}}$ & $\boldsymbol{S}_{\boldsymbol{b}}$ \\
\hline Low dispersity micelle & $\mathrm{y}=35.61 \mathrm{x}+10.1 \mathrm{~s} 2$ & 0.9957 & 1.35 \\
\hline
\end{tabular}




\section{Use of Living CDSA for the preparation of low dispersity PFTMC $15-b$-PEG P20 $_{1 D}$ fiber-like micelles of different lengths}

a

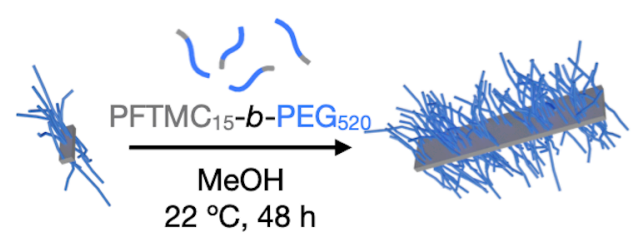

b

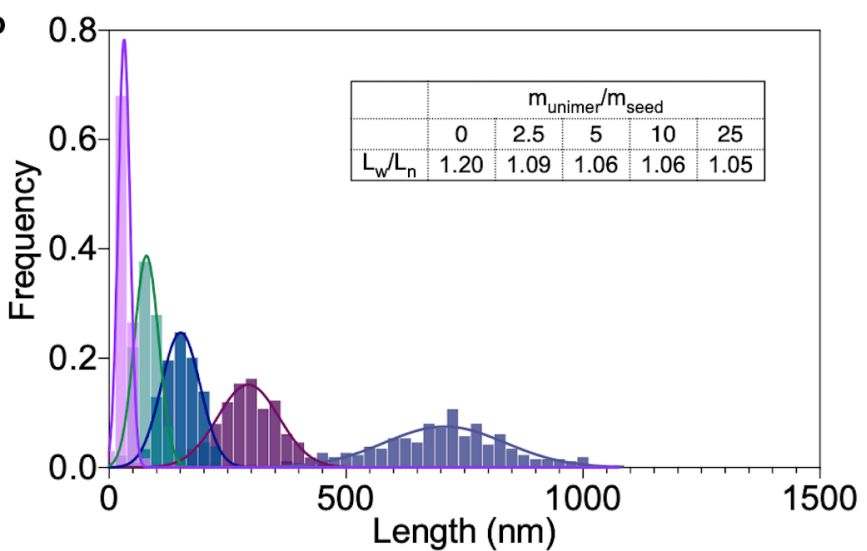

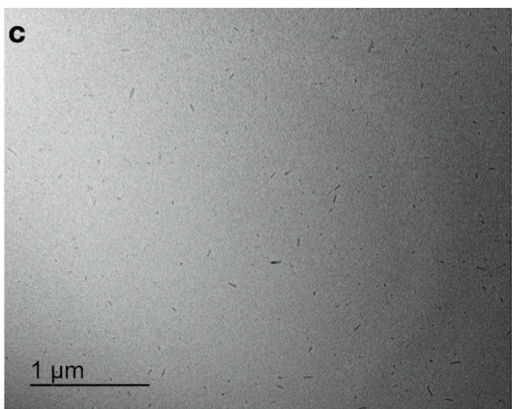

f

$1 \mu \mathrm{m}$

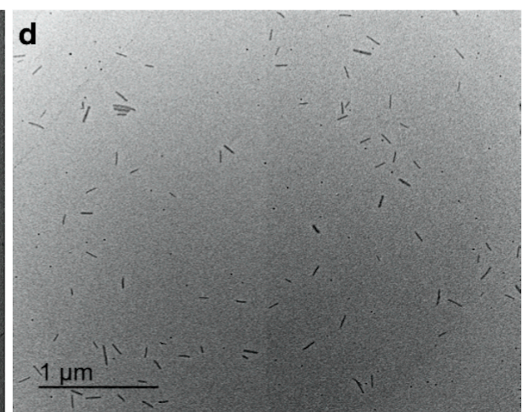

g

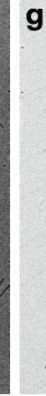

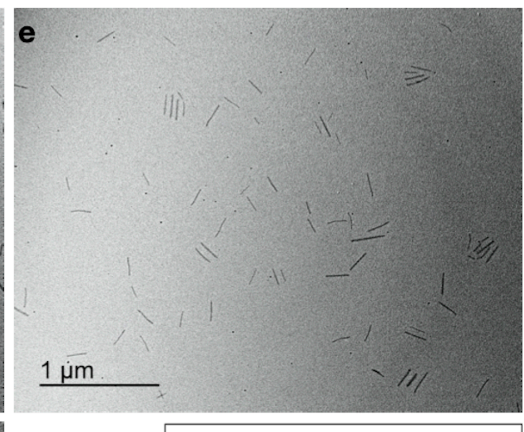

h

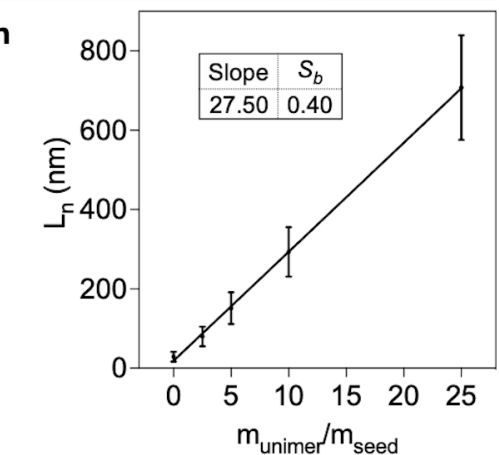

Figure S6. Living CDSA of PFTMC ${ }_{15}-b-\mathrm{PEG}_{520}$ in methanol with varying $m_{\text {unimer }} / m_{\text {seed }}$ ratio for preparing low dispersity 1D fiber-like micelles. Unimer was added in DMSO (a) Schematic representation of experiment design. Experiments were performed with $0.025 \mathrm{mg} / \mathrm{mL}$ seeds micelles at ambient temperature $\left(22^{\circ} \mathrm{C}\right)$ for $48 \mathrm{~h}$. (b) Statistical analysis (histograms and nonlinear regressions based on a Gaussian function) of micelle length distribution after living CDSA. The inset shows the polydispersity index (PDI $\left.=L_{w} / L_{n}\right)$ of each sample. $(\mathrm{c}-\mathrm{g})$ Bright field TEM micrographs of dried 1D micelle mixture after living CDSA with $m_{\text {unimer }} / m_{\text {seed }}=0,2.5,5,10$, and 25 respectively. The seed $L_{n}=28.8 \mathrm{~nm}$ and corresponds to $m_{\text {unimer }} / m_{\text {seed }}=0$. (h) Linear regression of $L_{n}$ values upon different $m_{\text {unimer }} / m_{\text {seed }}$ ratio. Error bars represent standard deviation of the micelle length distribution. The inset shows the slope and $S_{b}$ (standard error) value for linear regression. 
Table S5. Statistical analysis of micelle length distribution after living CDSA of $\mathrm{PFTMC}_{15}-b-\mathrm{PEG}_{520}$ for preparing low dispersity $1 \mathrm{D}$ fiber-like micelles. $\sigma$ represents the standard deviation of the micelle length distribution.

\begin{tabular}{|c|c|c|c|c|c|}
\hline $\mathbf{m}_{\text {unimer }} / \mathbf{m}_{\text {seed }}$ & $\mathbf{0}$ (seeds) & $\mathbf{2 . 5}$ & $\mathbf{5}$ & $\mathbf{1 0}$ & $\mathbf{2 5}$ \\
\hline $\boldsymbol{L}_{\boldsymbol{n}}(\mathbf{n m})$ & 28.8 & 79.8 & 151.1 & 293.1 & 707.6 \\
\hline $\boldsymbol{\sigma}(\mathbf{n m})$ & 12.4 & 25.0 & 41.1 & 62.6 & 132.0 \\
\hline Theoretical predicted $\boldsymbol{L}_{\boldsymbol{n}} \mathbf{( n m )}$ & 28.8 & 100.8 & 172.8 & 316.8 & 748.8 \\
\hline
\end{tabular}

Table S6. Linear regression of $L_{n}$ values upon different $m_{\text {unimer }} / m_{\text {seed }}$ ratio after living CDSA of PFTMC 15 $b$-PEG ${ }_{520}$ for preparing low dispersity $1 \mathrm{D}$ fiber-like micelles. $S_{b}$ represents the standard error of the slope.

\begin{tabular}{|l|c|c|c|}
\hline & Equation & $\mathbf{R}^{\mathbf{2}}$ & $\boldsymbol{S}_{\boldsymbol{b}}$ \\
\hline Low dispersity micelle & $\mathrm{y}=27.50 \mathrm{x}+18.45$ & 0.9994 & 0.40 \\
\hline
\end{tabular}


Statistical analysis of living CDSA by using two-different lengths of $\mathrm{PFS}_{26}-\boldsymbol{b}-\mathrm{P2} \mathrm{VP}_{325}$ seed micelles at ambient temperature $\left(22^{\circ} \mathrm{C}\right)$

Table S7. Statistical analysis of micelle length distribution after living CDSA by using two-different lengths of $\mathrm{PFS}_{26}-b-\mathrm{P} 2 \mathrm{VP}_{325}$ seed micelles at ambient temperature $\left(22{ }^{\circ} \mathrm{C}\right) . \sigma$ represents the standard deviation of the micelle length distribution. $m_{\text {seed }}$ represents the mass of original (ca. $17.1 \mathrm{~nm}$ ) seeds used for preparing the low dispersity ca. $100 \mathrm{~nm}$ and ca. $1000 \mathrm{~nm}$ micelle samples.

\begin{tabular}{|c|c|c|c|c|c|c|}
\hline \multirow{2}{*}{$\mathbf{m}_{\text {unimer }} / \mathbf{m}_{\text {seed }}$} & \multicolumn{3}{|c|}{ Short micelles } & \multicolumn{3}{c|}{ Long micelles } \\
\cline { 2 - 8 } & \multirow{3}{*}{$L_{n}(\mathrm{~nm})$} & $\sigma(\mathrm{nm})$ & $\begin{array}{c}\text { Theoretical } \\
\text { predicted } \\
L_{n}(\mathrm{~nm})\end{array}$ & $L_{n}(\mathrm{~nm})$ & $\sigma(\mathrm{nm})$ & $\begin{array}{c}\text { Theoretical } \\
\text { predicted } \\
\end{array}$ \\
\hline $\mathbf{0}$ & 113.7 & 25.7 & N/A & 1015.6 & 105.5 & N/A \\
\hline $\mathbf{1 0}$ & 307.9 & 67.6 & 284.7 & 1215.4 & 142.6 & 1186.6 \\
\hline $\mathbf{2 0}$ & 457.9 & 73.4 & 455.7 & 1355.2 & 121.8 & 1357.6 \\
\hline $\mathbf{3 0}$ & 615.4 & 89.1 & 626.7 & 1530.8 & 155.8 & 1528.6 \\
\hline
\end{tabular}

Table S8. Newly grown lengths on two-different lengths of $\mathrm{PFS}_{26}-b-\mathrm{P} 2 \mathrm{VP}_{325}$ micelles after living CDSA at ambient temperature $\left(22^{\circ} \mathrm{C}\right) . \sigma$ represents the standard deviation of newly grown length. $S D_{\bar{x}}$ represents the standard deviations of population mean (the experimental $L_{n}$ values) of newly grown length.

\begin{tabular}{|c|c|c|c|c|c|c|}
\hline $\begin{array}{c}\mathbf{m}_{\text {unimer }} \\
/ \mathbf{m}_{\text {seed }}\end{array}$ & $\begin{array}{c}\text { Newly grown } \\
\text { length (nm) } \\
\text { (short micelles) }\end{array}$ & $\begin{array}{c}\boldsymbol{\sigma} \\
\mathbf{( n m )}\end{array}$ & $\begin{array}{c}\boldsymbol{S} \boldsymbol{D}_{\overline{\boldsymbol{x}}} \\
\mathbf{( n m )}\end{array}$ & $\begin{array}{c}\text { Newly grown } \\
\text { length (nm) } \\
\text { (long micelles) }\end{array}$ & $\begin{array}{c}\boldsymbol{\sigma} \\
\mathbf{( n m )}\end{array}$ & $\begin{array}{c}\boldsymbol{S} \boldsymbol{D}_{\overline{\boldsymbol{x}}} \\
\mathbf{( n m})\end{array}$ \\
\hline $\mathbf{1 0}$ & 194.2 & 62.5 & 5.6 & 199.8 & 95.9 & 6.8 \\
\hline $\mathbf{2 0}$ & 344.2 & 68.8 & 4.1 & 339.6 & 60.9 & 6.3 \\
\hline $\mathbf{3 0}$ & 501.7 & 85.3 & 7.1 & 515.2 & 114.6 & 7.2 \\
\hline
\end{tabular}

Table S9. Linear regression of $L_{n}$ values upon different $m_{\text {unimer }} / m_{\text {seed }}$ ratio after living CDSA by using twodifferent lengths of $\mathrm{PFS}_{26}-b-\mathrm{P} 2 \mathrm{VP}_{325}$ seed micelles at ambient temperature $\left(22{ }^{\circ} \mathrm{C}\right) . S_{b}$ represents the standard error of the slope.

\begin{tabular}{|c|c|c|c|}
\hline & Equation & $\mathbf{R}^{2}$ & $\boldsymbol{S}_{\boldsymbol{b}}$ \\
\hline Short micelle & $\mathrm{y}=16.55 \mathrm{x}+125.47$ & 0.9966 & 0.69 \\
\hline Long micelle & $\mathrm{y}=16.85 \mathrm{x}+1026.43$ & 0.9957 & 0.78 \\
\hline
\end{tabular}




\section{Experiment at elevated temperature $\left(35^{\circ} \mathrm{C}\right)$ : living CDSA by using two-different lengths of $\mathrm{PFS}_{26}-b-\mathrm{P2VP}_{325}$ seed micelles at elevated temperature $\left(35^{\circ} \mathrm{C}\right)$}

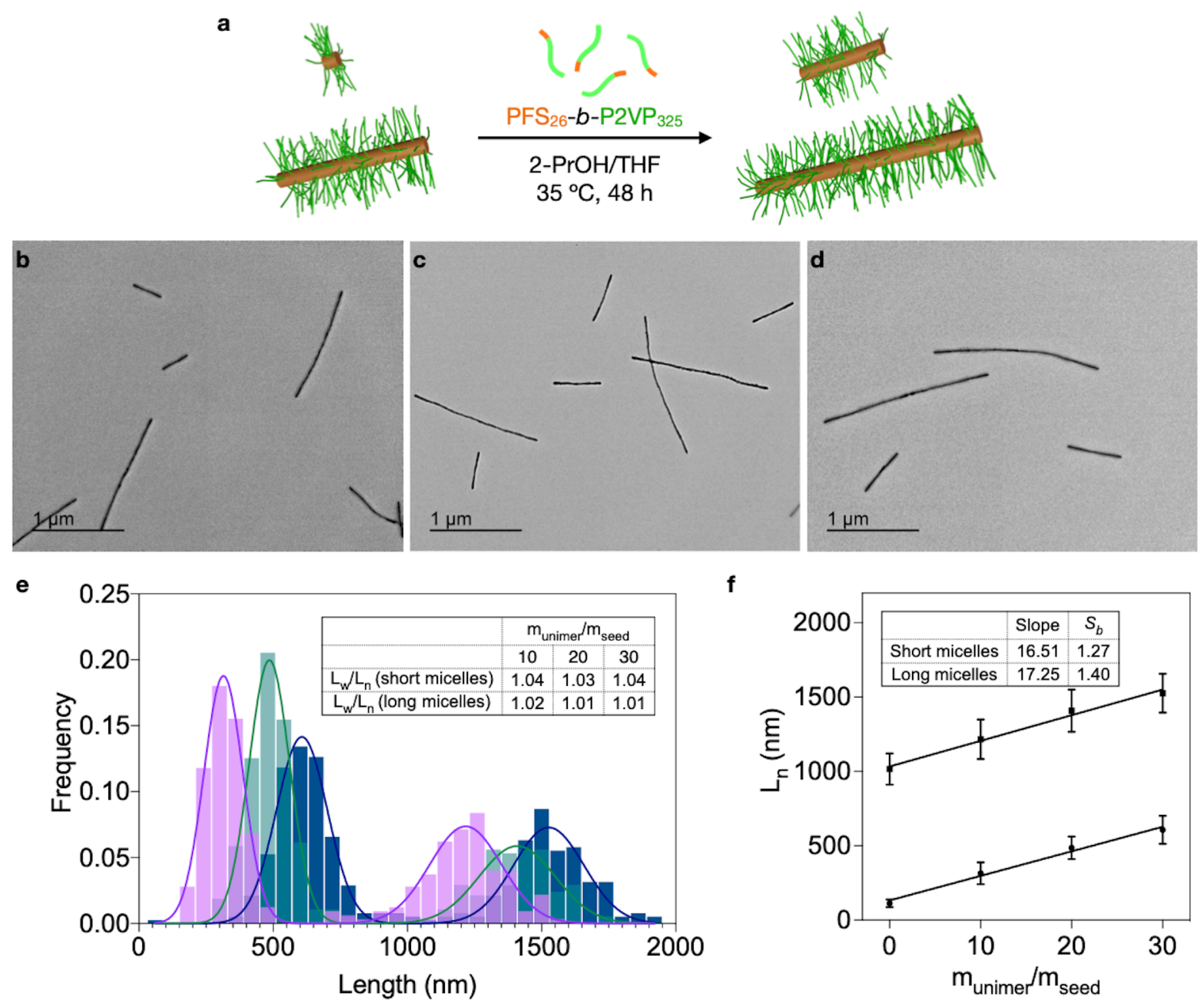

Figure S7. Living CDSA by using $\mathrm{PFS}_{26}-b-\mathrm{P} 2 \mathrm{VP}_{325}$ unimer and two-different lengths of $\mathrm{PFS}_{26}-b-\mathrm{P}_{2} \mathrm{VP}_{325}$ seed micelles $\left(L_{n}=113.7\right.$ and $\left.1015.6 \mathrm{~nm}\right)$ in $90 \% \mathrm{v} / \mathrm{v}$ isopropanol $/$ THF with varying $m_{\text {unimer }} / m_{\text {seed }}$ ratio. Experiments were performed at elevated temperature $\left(35^{\circ} \mathrm{C}\right)$ for $48 \mathrm{~h}$. (a) Schematic representation of experiment design. (b-d) Bright field TEM micrographs of dried 1D fiber-like micelle mixture after living CDSA with $m_{\text {unimer }} / m_{\text {seed }}=10,20$, and 30 respectively. $m_{\text {seed }}$ represents the mass of original (ca. $17.1 \mathrm{~nm}$ ) seeds used for preparing the low dispersity ca. $100 \mathrm{~nm}$ and ca. $1000 \mathrm{~nm}$ micelle samples. (e) Statistical analysis (histograms and nonlinear regressions based on a bivariate Gaussian function) of micelle length distribution after living CDSA. The inset shows the polydispersity index (PDI $=L_{w} / L_{n}$ ) of each sample. (f) Linear regression of $L_{n}$ values upon different $m_{\text {unimer }} / m_{\text {seed }}$ ratio. Error bars represent standard deviation of the micelle length distribution. The inset shows the slope and $S_{b}$ (standard error) value for linear regression. 
Table S10. Statistical analysis of micelle length distribution after living CDSA by using two-different lengths of $\mathrm{PFS}_{26}-b-\mathrm{P} 2 \mathrm{VP}_{325}$ seed micelles at elevated temperature $\left(35^{\circ} \mathrm{C}\right) . \sigma$ represents the standard deviation of the micelle length distribution. $m_{\text {seed }}$ represents the mass of original (ca. $17.1 \mathrm{~nm}$ ) seeds used for preparing the low dispersity ca. $100 \mathrm{~nm}$ and ca. $1000 \mathrm{~nm}$ micelle samples.

\begin{tabular}{|c|c|c|c|c|c|c|}
\hline \multirow{2}{*}{$\mathbf{m}_{\text {unimer }} / \mathbf{m}_{\text {seed }}$} & \multicolumn{3}{|c|}{ Short micelles } & \multicolumn{3}{c|}{ Long micelles } \\
\cline { 2 - 8 } & & & & Theoretical & & Theoretical \\
& $(\mathrm{nm})$ & $\sigma(\mathrm{nm})$ & $\begin{array}{c}\text { predicted } \\
L_{n}(\mathrm{~nm})\end{array}$ & $L_{n}(\mathrm{~nm})$ & $\sigma(\mathrm{nm})$ & $\begin{array}{c}\text { predicted } \\
L_{n}(\mathrm{~nm})\end{array}$ \\
\hline $\mathbf{0}$ & 113.7 & 25.7 & N/A & 1015.6 & 105.5 & N/A \\
\hline $\mathbf{1 0}$ & 314.7 & 72.9 & 284.7 & 1217.0 & 133.8 & 1186.6 \\
\hline $\mathbf{2 0}$ & 485.9 & 75.7 & 455.7 & 1408.9 & 142.1 & 1357.6 \\
\hline $\mathbf{3 0}$ & 607.0 & 95.2 & 626.7 & 1526.6 & 131.3 & 1528.6 \\
\hline
\end{tabular}

Table S11. Newly grown lengths on two-different lengths of $\mathrm{PFS}_{26}-b-\mathrm{P} 2 \mathrm{VP}_{325}$ micelles after living CDSA at elevated temperature $\left(35^{\circ} \mathrm{C}\right) . \sigma$ represents the standard deviation of newly grown length. $S D_{\bar{x}}$ represents the standard deviations of population mean (the experimental $L_{n}$ values) of newly grown length.

\begin{tabular}{|c|c|c|c|c|c|c|}
\hline $\begin{array}{c}\mathbf{m}_{\text {unimer }} \\
/ \mathbf{m}_{\text {seed }}\end{array}$ & $\begin{array}{c}\text { Newly grown } \\
\text { length (nm) } \\
\text { (short micelles) }\end{array}$ & $\begin{array}{c}\sigma \\
(\mathrm{nm})\end{array}$ & $\begin{array}{l}S D_{\bar{x}} \\
(\mathbf{n m})\end{array}$ & $\begin{array}{c}\text { Newly grown } \\
\text { length (nm) } \\
\text { (long micelles) }\end{array}$ & $\begin{array}{c}\sigma \\
(\mathrm{nm})\end{array}$ & $\begin{array}{l}S D_{\bar{x}} \\
(\mathrm{~nm})\end{array}$ \\
\hline 10 & 201.0 & 68.2 & 5.7 & 201.4 & 82.3 & 6.1 \\
\hline 20 & 372.2 & 71.2 & 9.6 & 393.3 & 95.2 & 11.7 \\
\hline 30 & 493.3 & 91.7 & 8.4 & 511.0 & 78.2 & 10.8 \\
\hline
\end{tabular}

Table S12. Linear regression of $L_{n}$ values upon different $m_{\text {unimer }} / m_{\text {seed }}$ ratio after living CDSA by using twodifferent lengths of $\mathrm{PFS}_{26}-b-\mathrm{P}_{2} \mathrm{VP}_{325}$ seed micelles at elevated temperature $\left(35^{\circ} \mathrm{C}\right) . S_{b}$ represents the standard error of the slope.

\begin{tabular}{|c|c|c|c|}
\hline & Equation & $\mathbf{R}^{\mathbf{2}}$ & $\boldsymbol{S}_{\boldsymbol{b}}$ \\
\hline Short micelle & $\mathrm{y}=16.51 \mathrm{x}+132.61$ & 0.9883 & 1.27 \\
\hline Long micelle & $\mathrm{y}=17.25 \mathrm{x}+1033.29$ & 0.9870 & 1.40 \\
\hline
\end{tabular}




\section{Exploration of the growth behavior for 1D fiber-like BCP micelles in a non-polar solvent medium by using two-different lengths of $\mathrm{PFS}_{50}-b$-PDMS 375 seed micelles}

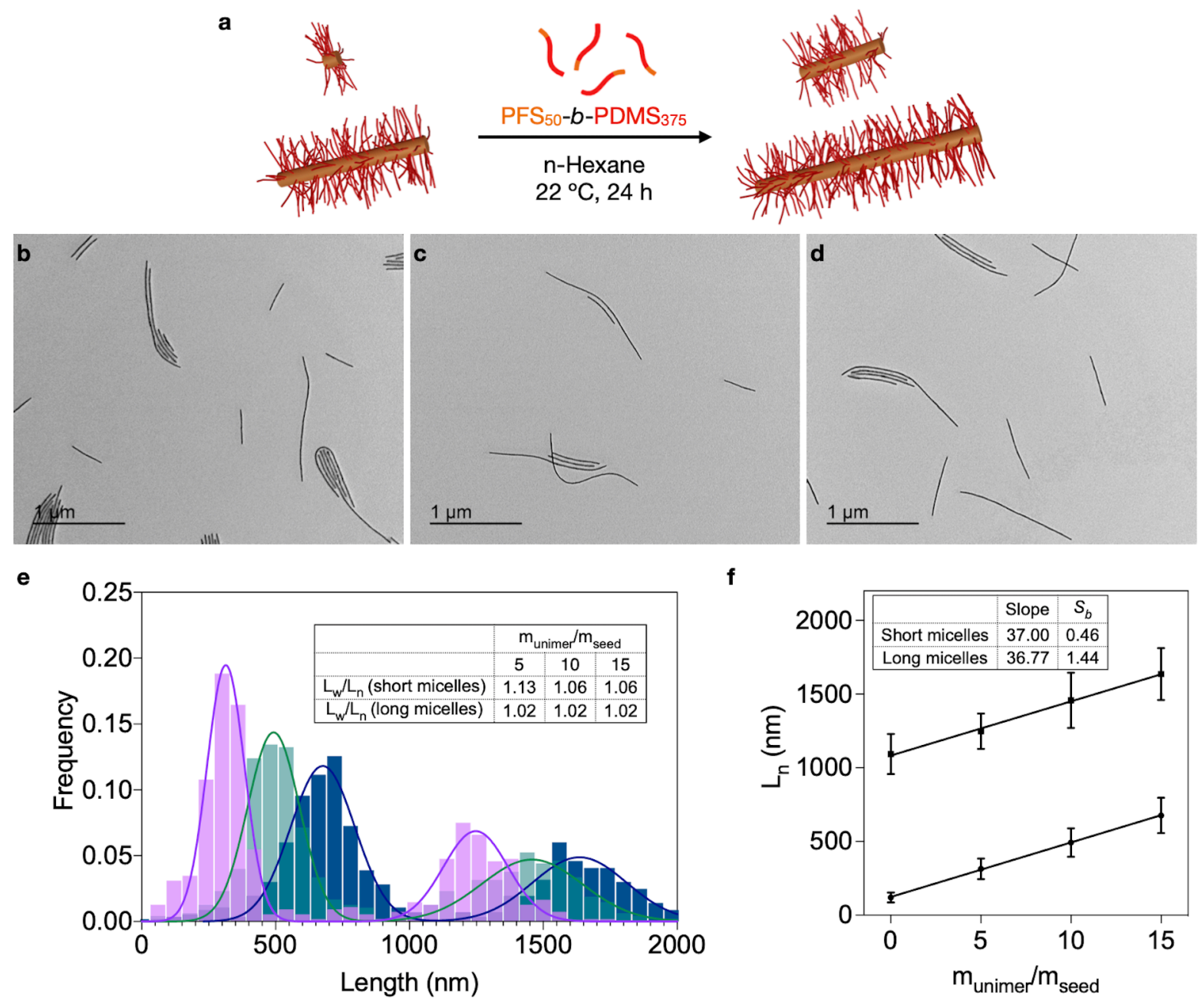

Figure S8. Living CDSA by using $\mathrm{PFS}_{50}-b-\mathrm{PDMS}_{375}$ unimer and two-different lengths of $\mathrm{PFS}_{50}-b-\mathrm{PDMS}_{375}$ seed micelle $\left(L_{n}=119.1\right.$ and $\left.1092.8 \mathrm{~nm}\right)$ in n-hexane with varying $m_{\text {unimer }} / m_{\text {seed }}$ ratio. Experiments were performed at $22{ }^{\circ} \mathrm{C}$ for $24 \mathrm{~h}$. Unimer was added in THF (a) Schematic representation of experiment design. (b-d) Bright field TEM micrographs of dried 1D fiber-like micelle mixture after living CDSA with $m_{\text {unimer }} / m_{\text {seed }}=10,20$, and 30 respectively. $m_{\text {seed }}$ represents the mass of original (ca. $35.9 \mathrm{~nm}$ ) seeds used for preparing the low dispersity ca. $100 \mathrm{~nm}$ and ca. $1000 \mathrm{~nm}$ micelle samples. (e) Statistical analysis (histograms and nonlinear regressions based on a bivariate Gaussian function) of micelle length distribution after living CDSA. The inset shows the polydispersity index (PDI $=L_{w} / L_{n}$ ) of each sample. (f) Linear regression of $L_{n}$ values upon different $m_{\text {unimer }} / m_{\text {seed }}$ ratio. Error bars represent standard deviation of the micelle length distribution. The inset shows the slope and $S_{b}$ (standard error) value for linear regression. 
Table S13. Statistical analysis of micelle length distribution after living CDSA by using two-different lengths of $\mathrm{PFS}_{50}-b$-PDMS 375 seed micelles at ambient temperature $\left(22{ }^{\circ} \mathrm{C}\right) . \sigma$ represents the standard deviation of the micelle length distribution. $m_{\text {seed }}$ represents the mass of original (ca. $35.9 \mathrm{~nm}$ ) seeds used for preparing the low dispersity ca. $100 \mathrm{~nm}$ and ca. $1000 \mathrm{~nm}$ micelle samples.

\begin{tabular}{|c|c|c|c|c|c|c|}
\hline \multirow{2}{*}{$\mathbf{m}_{\text {unimer }} / \mathbf{m}_{\text {seed }}$} & \multicolumn{3}{|c|}{ Short micelles } & \multicolumn{3}{c|}{ Long micelles } \\
\cline { 2 - 7 } & \multirow{2}{*}{$L_{n}(\mathrm{~nm})$} & $\sigma(\mathrm{nm})$ & $\begin{array}{c}\text { Theoretical } \\
\text { predicted } \\
L_{n}(\mathrm{~nm})\end{array}$ & $L_{n}(\mathrm{~nm})$ & $\sigma(\mathrm{nm})$ & $\begin{array}{c}\text { Theoretical } \\
\text { predicted } \\
\end{array}$ \\
\hline $\mathbf{0}$ & 119.1 & 33.8 & $\mathrm{~N} / \mathrm{A}$ & 1092.8 & 135.9 & N/A \\
\hline $\mathbf{5}$ & 313.9 & 70.1 & 298.6 & 1247.6 & 120.5 & 1272.3 \\
\hline $\mathbf{1 0}$ & 492.6 & 96.9 & 478.1 & 1457.9 & 187.8 & 1451.8 \\
\hline $\mathbf{s 1 5}$ & 676.2 & 120.2 & 657.6 & 1635.6 & 175.5 & 1631.3 \\
\hline
\end{tabular}

Table S14. Newly grown lengths on two-different lengths of $\mathrm{PFS}_{50}-b$-PDMS 375 micelles after living CDSA at ambient temperature $\left(22^{\circ} \mathrm{C}\right)$. $\sigma$ represents the standard deviation of newly grown length. $S D_{\bar{x}}$ represents the standard deviations of population mean (the experimental $L_{n}$ values) of newly grown length.

\begin{tabular}{|c|c|c|c|c|c|c|}
\hline $\begin{array}{c}\mathbf{m}_{\text {unimer }} \\
\mathbf{m}_{\text {seed }}\end{array}$ & $\begin{array}{c}\text { Newly grown } \\
\text { length (nm) } \\
\text { (short micelles) }\end{array}$ & $\begin{array}{c}\boldsymbol{\sigma} \\
\mathbf{( n m )}\end{array}$ & $\begin{array}{c}\boldsymbol{S D}_{\overline{\boldsymbol{x}}} \\
\mathbf{( n m )}\end{array}$ & $\begin{array}{c}\text { Newly grown } \\
\text { length (nm) } \\
\text { (long micelles) }\end{array}$ & $\begin{array}{c}\boldsymbol{\sigma} \\
\mathbf{( n m )}\end{array}$ & $\begin{array}{c}\boldsymbol{S} \boldsymbol{D}_{\overline{\boldsymbol{x}}} \\
\mathbf{( n m})\end{array}$ \\
\hline $\mathbf{5}$ & 194.8 & 61.4 & 4.3 & 154.8 & N/A & N/A \\
\hline $\mathbf{1 0}$ & 373.5 & 90.8 & 8.1 & 365.1 & 129.6 & 6.8 \\
\hline $\mathbf{1 5}$ & 557.1 & 115.3 & 6.7 & 542.8 & 111.0 & 7.8 \\
\hline
\end{tabular}

Table S15. Linear regression of $L_{n}$ values upon different $m_{\text {unimer }} / m_{\text {seed }}$ ratio after living CDSA by using twodifferent lengths of $\mathrm{PFS}_{50}-b-\mathrm{PDMS}_{375}$ seed micelles at ambient temperature $\left(22^{\circ} \mathrm{C}\right) . S_{b}$ represents the standard error of the slope.

\begin{tabular}{|c|c|c|c|}
\hline & Equation & $\mathbf{R}^{\mathbf{2}}$ & $\boldsymbol{S}_{\boldsymbol{b}}$ \\
\hline Short micelle & $\mathrm{y}=37.00 \mathrm{x}+122.95$ & 0.9997 & 0.46 \\
\hline Long micelle & $\mathrm{y}=36.77 \mathrm{x}+1082.66$ & 0.9969 & 1.44 \\
\hline
\end{tabular}


Statistical analysis of living CDSA by using two-different lengths of PFS $50-b-$ PDMS $_{375}$ seed micelles then growing $\mathrm{PFS}_{26}-b-\mathrm{P}_{2} \mathrm{VP}_{325}$ unimer for preparing triblock co-micelles

Table S16. Statistical analysis of micelle length distribution after living CDSA of triblock co-micelles. $\sigma$ represents the standard deviation of the micelle length distribution. $\mathrm{m}_{\text {seed }}$ represents the mass of original (ca. $17.1 \mathrm{~nm}) \mathrm{PFS}_{26}-b-\mathrm{P} 2 \mathrm{VP}_{325}$ seeds used for preparing the low dispersity ca. $100 \mathrm{~nm}$ and ca. $1000 \mathrm{~nm}$ micelle samples from this material. The incremental length increase detected (ca. $6.5 \mathrm{~nm}$ ) with each equivalent of added $\mathrm{PFS}_{26}-b-\mathrm{P}_{2} \mathrm{VP}_{325}$ unimer to the $\mathrm{PFS}_{50}-b$-PDMS ${ }_{375}$ seeds is substantially less than that observed when compositionally identical $\mathrm{PFS}_{26}-b-\mathrm{P}_{2} \mathrm{VP}_{325}$ seeds were used (ca.16.6 nm, Table S2). This is attributed to an increase in PFS core width as a result of the larger DP for the PFS block in the seeds in the former case $\left(\mathrm{PFS}_{50}-b-\mathrm{PDMS}_{375}: 50\right.$ vs $\left.\mathrm{PFS}_{26}-b-\mathrm{P} 2 \mathrm{VP}_{325}: 26\right)$.

\begin{tabular}{|c|c|c|c|c|}
\hline \multirow{2}{*}{$\mathbf{m}_{\text {unimer }} / \mathbf{m}_{\text {seed }}$} & \multicolumn{2}{|c|}{ Short micelles } & \multicolumn{2}{c|}{ Long micelles } \\
\cline { 2 - 5 } & $L_{n}(\mathrm{~nm})$ & $\sigma(\mathrm{nm})$ & $L_{n}(\mathrm{~nm})$ & $\sigma(\mathrm{nm})$ \\
\hline $\mathbf{0}$ & 103.3 & 36.1 & 1170.1 & 139.9 \\
\hline $\mathbf{2 0}$ & 215.6 & 47.8 & 1300.2 & 136.4 \\
\hline $\mathbf{4 0}$ & 360.8 & 67.2 & 1422.8 & 152.2 \\
\hline $\mathbf{6 0}$ & 479.0 & 75.5 & 1567.1 & 136.9 \\
\hline
\end{tabular}

Table S17. Newly grown lengths on two-different lengths of triblock co-micelles after living CDSA. $\sigma$ represents the standard deviation of newly grown length. $S D_{\bar{x}}$ represents the standard deviations of population mean (the experimental $L_{n}$ values) of newly grown length.

\begin{tabular}{|c|c|c|c|c|c|c|}
\hline $\begin{array}{c}\mathbf{m}_{\text {unimer }} \\
\text { /m }\end{array}$ & $\begin{array}{c}\text { Newly grown } \\
\text { length (nm) } \\
\text { (short micelles) }\end{array}$ & $\begin{array}{c}\boldsymbol{\sigma} \\
\mathbf{( n m )}\end{array}$ & $\begin{array}{c}\boldsymbol{S} \boldsymbol{D}_{\overline{\boldsymbol{x}}} \\
\mathbf{( n m )}\end{array}$ & $\begin{array}{c}\text { Newly grown } \\
\text { length (nm) } \\
\text { (long micelles) }\end{array}$ & $\begin{array}{c}\boldsymbol{\sigma} \\
\mathbf{( n m )}\end{array}$ & $\begin{array}{c}\boldsymbol{S} \boldsymbol{D}_{\overline{\boldsymbol{x}}} \\
\mathbf{( n m )}\end{array}$ \\
\hline $\mathbf{2 0}$ & 112.3 & 31.3 & 2.3 & 130.1 & N/A & N/A \\
\hline $\mathbf{4 0}$ & 257.5 & 56.7 & 4.3 & 252.7 & 59.9 & 5.4 \\
\hline $\mathbf{6 0}$ & 375.5 & 66.3 & 5.2 & 397.0 & N/A & N/A \\
\hline
\end{tabular}

Table S18. Linear regression of $L_{n}$ values upon different $m_{\text {unimer }} / m_{\text {seed }}$ ratio after living CDSA of triblock co-micelles. $S_{b}$ represents the standard error of the slope.

\begin{tabular}{|c|c|c|c|}
\hline & Equation & $\mathbf{R}^{\mathbf{2}}$ & $\boldsymbol{S}_{\boldsymbol{b}}$ \\
\hline Short micelle & $\mathrm{y}=6.36 \mathrm{x}+98.83$ & 0.9977 & 0.22 \\
\hline Long micelle & $\mathrm{y}=6.57 \mathrm{x}+1167.90$ & 0.9990 & 0.15 \\
\hline
\end{tabular}




\section{Statistical analysis of living CDSA by using two-different lengths of PFTMC P $_{15}-b$-PEG520 seed}

micelles

Table S19. Statistical analysis of micelle length distribution after living CDSA by using two-different lengths of PFTMC $_{15}-b-\mathrm{PEG}_{520}$ seed micelles. $\sigma$ represents the standard deviation of the micelle length distribution. $m_{\text {seed }}$ represents the mass of original (ca. $28.8 \mathrm{~nm}$ ) seeds used for preparing the low dispersity ca. $100 \mathrm{~nm}$ and ca. $1000 \mathrm{~nm}$ micelle samples.

\begin{tabular}{|c|c|c|c|c|c|c|}
\hline \multirow{2}{*}{$\mathbf{m}_{\text {unimer }} / \mathbf{m}_{\text {seed }}$} & \multicolumn{3}{|c|}{ Short micelles } & \multicolumn{3}{c|}{ Long micelles } \\
\cline { 2 - 7 } & \multirow{2}{*}{$L_{n}(\mathrm{~nm})$} & $\sigma(\mathrm{nm})$ & $\begin{array}{c}\text { Theoretical } \\
\text { predicted } \\
L_{n}(\mathrm{~nm})\end{array}$ & $L_{n}(\mathrm{~nm})$ & $\sigma(\mathrm{nm})$ & $\begin{array}{c}\text { Theoretical } \\
\text { predicted }\end{array}$ \\
\hline $\mathbf{0}$ & 79.8 & 25.0 & N/A & 707.6 & 132.0 & N/A \\
\hline $\mathbf{5}$ & 219.3 & 76.0 & 223.8 & 830.6 & 123.3 & 851.6 \\
\hline $\mathbf{1 0}$ & 377.3 & 75.8 & 367.8 & 1005.9 & 143.7 & 995.6 \\
\hline $\mathbf{1 5}$ & 501.1 & 106.9 & 511.8 & 1130.3 & 163.4 & 1139.6 \\
\hline
\end{tabular}

Table S20. Newly grown lengths on two-different lengths of PFTMC $15-b-\mathrm{PEG}_{520}$ micelles after living CDSA. $\sigma$ represents the standard deviation of newly grown length. $S D_{\bar{x}}$ represents the standard deviations of population mean (the experimental $L_{n}$ values) of newly grown length.

\begin{tabular}{|c|c|c|c|c|c|c|}
\hline $\begin{array}{c}\mathbf{m}_{\text {unimer }} \\
/ \mathbf{m}_{\text {seed }}\end{array}$ & $\begin{array}{c}\text { Newly grown } \\
\text { length (nm) } \\
\text { (short micelles) }\end{array}$ & $\begin{array}{c}\boldsymbol{\sigma} \\
\mathbf{( n m})\end{array}$ & $\begin{array}{c}\boldsymbol{S} \boldsymbol{D}_{\overline{\boldsymbol{x}}} \\
\mathbf{( n m )}\end{array}$ & $\begin{array}{c}\text { Newly grown } \\
\text { length (nm) } \\
\text { (long micelles) }\end{array}$ & $\begin{array}{c}\boldsymbol{\sigma} \\
\mathbf{( n m )}\end{array}$ & $\begin{array}{c}\boldsymbol{S} \boldsymbol{D}_{\overline{\boldsymbol{x}}} \\
\mathbf{( n m )}\end{array}$ \\
\hline $\mathbf{5}$ & 139.5 & 71.8 & 5.0 & 123.0 & N/A & N/A \\
\hline $\mathbf{1 0}$ & 297.5 & 71.6 & 5.2 & 298.3 & 56.8 & 4.5 \\
\hline $\mathbf{1 5}$ & 421.3 & 103.9 & 6.5 & 422.7 & 96.3 & 6.8 \\
\hline
\end{tabular}

Table S21. Linear regression of $L_{n}$ values upon different $m_{\text {unimer }} / m_{\text {seed }}$ ratio after living CDSA by using twodifferent lengths of $\mathrm{PFTMC}_{15}-b$ - $\mathrm{PEG}_{520}$ seed micelles at ambient temperature $\left(22^{\circ} \mathrm{C}\right) . S_{b}$ represents the standard error of the slope.

\begin{tabular}{|c|c|c|c|}
\hline & Equation & $\mathbf{R}^{2}$ & $\boldsymbol{S}_{\boldsymbol{b}}$ \\
\hline Short micelle & $\mathrm{y}=28.44 \mathrm{x}+81.09$ & 0.9976 & 0.90 \\
\hline Long micelle & $\mathrm{y}=28.85 \mathrm{x}+702.16$ & 0.9932 & 1.47 \\
\hline
\end{tabular}




\section{References}

(1) Harrisson, S. The Downside of Dispersity: Why the Standard Deviation Is a Better Measure of Dispersion in Precision Polymerization. Polym. Chem. 2018, 9 (12), 1366-1370. 